\title{
Establishing a Link between Support Offered for Foundation Provisioning and in Mainstream
}

\author{
S. Ntlabathi \\ University of Fort Hare, Alice, South Africa \\ E-mail: sntlabath@ufh.ac.za
}

\section{Doi:10.5901/mjss.2014.v5n11p185}

\section{Abstract}

Foundation provisioning is one strategy that the South African Higher Education Institutions(HEI) have developed in order to enable access to the previously marginalized student population and to address the articulation gap. However what's worrying is that students admitted in mainstream programmes are also from the same previously marginalized population and experienced the same articulation gap. A qualitative approach within a case study framed this study using a survey in the format of an open ended questionnaire. Data was sourced from hundred and seventy three of the three hundred sample of students, which equals fifty eight percent of the sample in four faculties in order to determine; a) challenges faced by students in both mainstream and foundation; b) benefits as articulated by students in both mainstream and foundation programmes. The study used Activity theory as an analytic framework to explore the benefits and challenges of being a foundation student as opposed to being a mainstream student. Activity Theory seems more appropriate for this research, as it caters well for the complexity and diversity that may be presented by the two systems. The results show that there are common challenges of academic literacy, workload and career choice. However no clear strategy exists for alignment of content between the two groups. The study recommends that there be rethinking on curriculum alignment, to ensure that the students exit with the requisite skills. All these students require substantial curriculum space and time for positive development.

Keywords: Foundation provisioning, Higher Education, Articulation gap, Mainstream, Activity theory.

\section{Introduction}

Foundation provisioning is not a thing of the 20 $0^{\text {th }}$ century, it existed since the 1980's in the South African Higher Education landscape in the form of bridging programmes (Scott, 2009). But then the focus was different in that science and medical students benefited the most. It was still meant to address access for success for students who qualify for higher education but may not necessarily meet all the entry requirements for a particular discipline. What we have now as Foundation Provisioning in our Higher Education Institutions (HEI) is a result of the challenges of massification. Massification in Higher Education institutions, specifically Universities was a strategy to address inequality and equity issues which resulted in many disadvantaged students not getting access into Higher Education. Massification bought with it a lot of challenges which included incomparable levels of diversity, low pass rates, and high dropout rates (Scott, Yeld, and Hendry, 2007). According to Strydom, Mentz, \& Kuh, (2010) the massification trend seen in higher education internationally, has led to a rapid increase in the number of students matriculating and gaining access to South African universities. Between 1993 and 2002, the number of African students matriculating increased by a third, from 40\% to $60 \%$. Despite widening access, overall participation rates in South African higher education remain low at $16 \%$ in 2005 , a predicted $17.5 \%$ for 2010 and a goal of $20 \%$ participation by 2015 (Department of Education, 2001). While this achievement is noteworthy, the same cannot be said about higher education graduation rates (Jansen 2004, as cited by Strydom et al, 2010).

SAPA, (2008) shows a preliminary data analysis of the 2005 cohort of the university sector has shown that the drop-out rates of first time entering students in a 3-year qualification are on average $26 \%$ in the first year, with a further $9 \%$ in the second year and $6 \%$ in the third year, while for a 4-year qualification, the average drop-out rates for first time entering students are 15\% in the first year, with a further 7\% in the second year, $4 \%$ in the third year and $3 \%$ in the fourth year. To curb these challenges and assist universities the Department of Higher Education further introduced Foundation provisioning for all University faculties. Before we go further, below are a few definitions of the major terms used in this study:

- Foundation provision: Offering of courses or other curricular elements that are intended to equip un/underprepared students with academic foundations that will enable them to successfully complete a 
university qualification that has been approved by the Minister of Higher Education and Training. (DOE , 2006: 2)

- Foundation student: He/she who meets the minimum statutory requirements for entrance into higher education \& enrolled for an Extended Curriculum Programme approved by the Department of Dept. of Higher Education for foundation provisioning (DOE , 2006: 2).

- Extended Curriculum Programme (ECP): Institutions' formal (i.e. ministerial approved) undergraduate degree/diploma programme in which substantial foundational provision, in which the coursework prescribed for the regular curriculum is incorporated. ( Department of Education, 2001).

- Mainstream student: For this study the working definition of a mainstream student is a student who meets all the requirements for entrance into higher education and is enrolled in a full degree programme.

According to Scott et al, (2007) the challenge is the articulation gap between what students admitted to Universities bring and the expectations of Universities. The articulation gap is characterised by issues of content and conceptual, approaches to learning, academic literacy and affective factors (Scott et al, 2007). CHE (2013:19) further argues that the articulation gap 'involves not only subject knowledge but also academic skills and literacies, approaches to study, background or contextual knowledge, and forms of social capital'. The question one could ponder is weather the articulation gap applied to the so called underprepared students only or to all students wanting access to Higher Education. This study understands mainstream students as students who qualify to enter into Higher Education Institutions. One would argue that mainstream students have gone through the same education system experienced by the foundation students? This research seeks to motivate that even mainstream students need to benefit from the support given to foundation students at their first year level, as the articulation gap has been experienced by all students entering Higher Education. This study is done at a South African Higher Education Institution which has introduced Foundation provisioning programmes in four of its faculties to give access to students wanting access to Higher Education studies. Foundation provisioning is defined as the offering of modules, courses or other curricular elements that are intended to equip underprepared students with academic foundations that will enable them to successfully complete a Higher Education qualification.

Foundation programmes follow different models at the different Higher Education Institutions in South Africa that are valid for different educational purposes and target groups. The four models as described in the Department of Education policy document are outlined below Department of Education, 2006:

Model 1, is a "fully foundational" course. The most common form of this is a course that is preparatory to the regular first-level course in the subject(s) concerned. In other words, foundation students complete this kind of course before proceeding to the regular first-year course in the subject concerned. Courses of this kind are commonly used in cases where the foundation students are very underprepared for the regular curriculum and are deemed to need extensive foundational teaching before they undertake the traditional first-year level.

Model 2, is an "extended" course, which combines regular course material with substantial foundational material and is substantially longer in duration than the corresponding regular course. An example of an extended course in, for example, Mathematics is a course that covers the same content as a semester mathematics course but is taught over the full year - incorporating substantial foundational provision - with the same contact time (say 5 contact periods) per week as the regular course.

Model 3, is an "augmented" course, which covers all the material of a regular course and has the same duration, but is taught separately and integrates substantial foundational material through additional formally-timetabled contact time. To meet the definition of a foundation course, the contact time of an augmented course must be approximately double that of the regular course.

Model 4, is an "augmenting" course, which allows for the foundational elements of an augmented course to be provided as a separate (but integrally linked) course or module. This kind of course thus provides for a variant of Model 3 that can be applied productively in certain subject areas and circumstances. The nature of the variant is as follows. By definition, an augmented course (model 3) must be taught separately, with its regular and foundational material fully integrated; this remains the educationally preferable model because it provides a high degree of flexibility in meeting student needs.

At this particular Higher Education Institution foundation provisioning programmes take the extended model of foundation provisioning in all four faculties that offer foundation programmes. As per definition of foundation programmes, this model allows more time, hence most are referred to as extended programmes. In year one, what a mainstream student would do over a semester ( 6 months), it is done over a year by a foundation student. 


\section{Theoretical Framework}

The study used Activity theory as an analytic framework to explore the benefits and challenges of being a foundation student as opposed to being a mainstream student. Activity Theory was invented by the Russian psychologist Lev S. Vygotsky (1934/1986) (Engeström, 1993). Later followed up by one of his students Leont'ev and then later by Engestrom. He held that historical-cultural school seeks to focus on a unit of analysis that captures the individual in context. 'Activity' is such a unit (Engeström, 1993). In Activity Theory the unit of analysis is an 'activity' based on the assumption that the human mind exists and develops within a context where humans interact with their environment in a meaningful, goalorientated and socially determined manner. An activity "is driven by various needs, in which people want to achieve a certain purpose (or goal)" and cannot be analysed outside of the context in which it occurs. Activity Theory seems appropriate for this research, as it caters well for dynamic change, provides research outcomes that have a high degree of relevance, is pragmatic, and can address complexity of systems well. Activity theory in this study is used for the analysis of data. Activity theory uses the Activity triangle. This study uses Leont'ev perspective of the Activity system triangle as an analytical framework. Leont'ev extended the original Activity Theory triangle developed by Vygotsky, in an attempt to include other aspects that may influence the individual in a community of practice. These socio-cultural aspects include rules, division of labour and community. Below is an example of Leont'ev Activity Theory Triangle showing the different components?

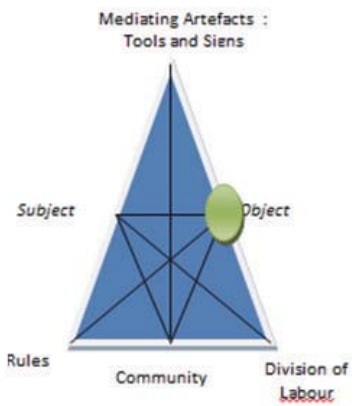

Figure 1: Adapted from Leon'tev's Activity System Triangle

\subsection{The Aim of the Study}

The aim of this study was to uncover the benefits and challenges of all students both mainstream and foundation that come to Higher Education, in order to determine the extent of support needed in both environments.

\subsection{The Research Question:}

The questions that were posed to students to further probe this goal:

1. In what way does student support for mainstream differ from support in foundation provisioning?

2. Describe the benefits of being a foundation student as opposed to a mainstream student?

3. Describe the benefits of being a mainstream student as opposed to a foundation student?

4. If you where choose between attending foundation or mainstream classes which would you choose and why?

\section{Research Methodology}

\subsection{Research Design}

A qualitative approach within a case study framed this study. A survey methodology in the format of an open ended questionnaire was used to gather data from first year foundation provisioning students and first year mainstream students. According to Jansen H, (2010) "a qualitative survey studies the diversity of a topic within a given population."

\subsection{Sampling and data collection}

Purposive sampling was done since this study was targeting foundation students and mainstream student at first year level in four faculties of the University. A pre-structured open-ended questionnaire was designed to solicit responses from 
students around the benefits and challenges of being a foundation student as opposed to a mainstream student. Three hundred questionnaires were distributed to students. Hundred and seventy three of the three hundred responded to the questionnaire, which equals fifty eight percent of the sample.

\subsection{Data Analysis}

Activity Theory was used to analyse the data, so as to separate foundation and mainstream students into two units of analysis or Activity Systems. This means all responses from foundation students were lumped together and those from mainstream were also lumped together. Each group of questionnaires was coded to come up with the thematic structure that would answer the research questions. The next section discusses the findings according to each Activity Systems and the themes therein.

\section{The Findings}

The findings are outlined according to each Activity System. The following two sections outline the findings according to the (1) Mainstream student's findings-Activity System and (2) Foundation students Findings-Activity System. The findings of the study are first categorised into the six components of Leont'ev Activity Theory Triangle. Leont'ev advocates the study of artefacts as integral and inseparable components of human functioning' (Engeström, 1993), but he argues that the focus of the study of mediation should be on its relationship with the other components of an activity system.

Leon'tev's activity system model is used to understand the subjects' experiences. This means for the subject to achieve the objective, they operate within a community with rules and division of labour which may work to enable or constrain the activities of the subject. How the different components of the activity system interact and impact each other is described in the sections that follow. The following sections offer an outline of each activity system.

\subsection{The Mainstream Students Activity Systems:}

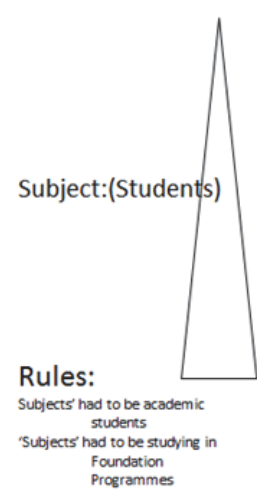

Tool: (everyone's orientation, lectures, tutorials)

Figure 2: Mainstream Activity System

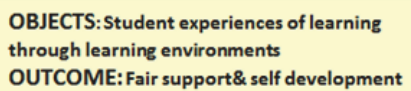

Community:

Lecturer/facilitator,

students, tutors, Administrator

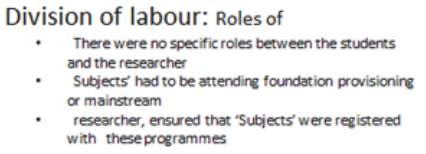

Division of labour: Roles of

There were no specific roles between the students and the researcher or mainstream with these programmes

The components of the above activity system read as follows; the subjects are mainstream students as their experience is understudy. The tools used by the students in their learning experience include attendance of classes, tutorials or practical's and consultations with the lecturer and other support departments like Student development and Language and writing centers as well as Supplemental Instruction facilitators etc within a semester for their $1^{\text {st }}$ modules. The community is that of the University which includes lecturers, faculty staff, peers and the university as a whole. The rules within this community include but are not limited to university policies, procedures and processes and well as faculty rules. Division of Labour within this community is such that students adhere to the rules and responsibilities as outlined by the faculty and university. Students themselves have a responsibility as registered students who are there to learn and to be participants and drivers of their learning. Lecturers also have their roles and responsibilities as per university policies, rules and regulations that they should adhere to.

The findings take the format of three main themes 1) learning and 2) support 3) identity. With respect to learning a lot of benefits were highlighted by the respondents. Educational tours were highlighted as one of the encouraging and 
motivating factors when doing foundation provisioning as compared to mainstream. I quote one of the responses verbatim "We also want educational tours". For these mainstream students this was an important feature in foundation programmes which they believe they would also benefit from. Educational tours are an experiential learning component of any learning activity, as students are able to see and experience what happens in a working environment. It enables them to link their theory to practice and ask relevant questions relating to their learning activities. Another positive aspects relating to foundation provisioning as highlighted by one of the mainstream respondents was that "They are really enjoying their $1^{\text {st }}$ year life at University". Meaning having all these extra mural activities enhances the foundation students $1^{\text {st }}$ year experience. Another common theme that relates to support given to foundation as opposed to mainstream is "We would also appreciate the support given to foundation students" and "There is not much assistance as compared to foundation". This seems to be another major benefit highlighted by mainstream students, that foundation students get a lot of assistance and support. Foundation students get a lot of time to do their modules as opposed to mainstream. Support is there for all students. Mainstream students are given support in different forms. Part of the support is enforced on them depending on their areas of weakness and some is left up to them to go for. It's more a matter of being aware that support is available for different articulation gaps in different units within the University. On the identity aspect of being a mainstream as opposed to a foundation students two major challenges were highlighted, which could be somewhat a positive for the mainstream student. 1) I quote this particular response "I do not want to be called foundation" mainly because there is some stigmatization attached to being a foundation student. Most respondents see this as a negative aspect as they see foundation students as those who had been just given a chance, they did not have the proper entrance results for Higher Education, or they are weak etc. 2) Another aspect from some respondents was that of the number of years, instead of spending three years you spend four years in University e.g "You have more years spent at varsity". This is a challenge to being a foundation student, you have to dead of to your degree in four years instead of three years. When one argues these two activity systems, you will find that there are benefits and challenges in both systems i.e. in both mainstream and foundation. It suggests that one has to weigh the benefits of one over the other.

\subsection{The Foundation Students Activity System}

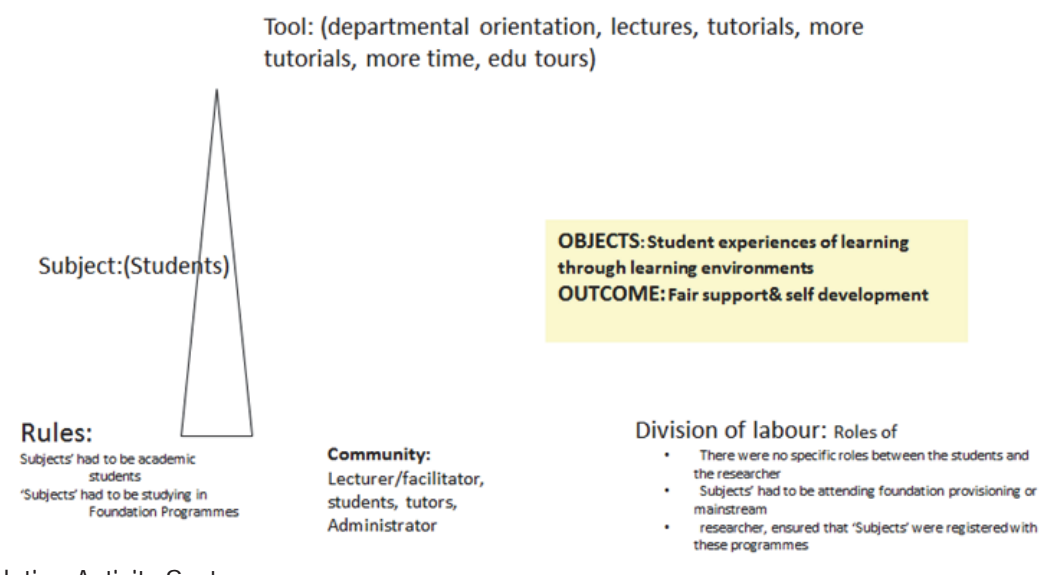

Figure 3: Foundation Activity System

The components of this activity system are similar to the mainstream as they function within the same community. The above Activity system is analysed as follows; the subjects are the foundation students as their experience is understudy. The tools used by the students in their learning experience include attendance of classes, tutorials or practicals and consultations with the lecturer and other support departments like Student development and Language and writing centres as well as Supplemental Instruction facilitators etc within a year for their $1^{\text {st }}$ year modules. The community is that of the HE institution which includes separate Lecturers, Faculty staff, peers and the University as a whole and a special coordinator for Foundation programmes. The rules within this community include but are not limited to University policies, procedures and processes and well as faculty rules. Division of Labour within this community is such that students adhere to the rules and responsibilities as outlined by the faculty and University plus those rules pertaining to the foundation coordinator office. Students themselves have a responsibility as registered students who are there to learn and to be participants and drivers of their learning. Lecturers also have their roles and responsibilities as per University 
policies and regulations that they should adhere to. The only extended factor within this foundation community is that there are separate classes for foundation students and more time and additional extra mural activities.

The discussion will follow the same three themes as above that is 1) learning and 2) support 3) identity. The benefits categorized under learning activities as outlined by the foundation respondents ranged from, I quote verbatim "More time and effort is given to us", "Our modules don't differ too much, pretty much the same, we just given more time". The whole issue of time talks to the whole ideology behind foundation provisioning. Foundation provisioning allows the students to do a semester course spread over a year, which gives the student enough time to engage with and understand the materials. In the area of support most responses are in line with the following excerpt "Being in Foundation helps a lot cause you have tutorials groups that make you understand what's going on". My understanding of a student academic life involves the attendance of tutorials whether you a foundation student or a mainstream student, the difference is that in foundation these are more structured and monitored that in mainstream were student do not attend sometimes. In the identity theme, foundation student highlighted their main constraint to be the stigma aligned to being registered in foundation. I quote one respondent "They treat us as if we are not qualified or we are Dom, yet we get higher percentages than them in tests". This suggest a form of inferiority towards foundation students. There is a positive component in this respondents excerpt as he/she feels they still get better grades than mainstream students even though they are in foundation or are seen as "Dom" or not being capable. The issue of the stigmatization and the issue of the duration of foundation programmes is a challenge for both foundation students and mainstream students who would appreciate the foundation experience.

\section{Discussion}

The results were outlined using three themes 1) learning, 2) support and 3) identity. Firstly in looking at the first theme which focused on learning, the results show that there are differential learning benefits in both programmes, in that one group has more time to cover the content than the other. Foundation students take one year to cover what mainstream students would cover in a semester. Yorke (2003) argued that the need to perform for summative assessments at the end of the first semester puts particular pressure on students who are acclimatizing and makes little sense when students merely have to pass the first year to qualify for the next year. Foundation students highlighted that more time and effort is given to them and that their modules do not differ too much as they are pretty much the same it is just that they (foundation students) are given more time than mainstream. Both groups had different views about this. This suggests that foundation students do realise some positive aspects or an added advantage in having more time for their learning. Warren, (2002) argues that students bring varying cognitive, linguistic, knowledge and cultural resources to the learning situation. Hence, they need to be guided or assisted - in ways appropriate to their potential - to develop the critical and communicative skills and the conceptual repertoires that will enable them to deal with academic tasks. The study would argue that time does play a major role in students learning capabilities. Another point that was highlighted by the mainstream students was that they felt it would also benefit them to go on educational tours which are only offered to foundation students. Education tours do play a big role in the education environment as an experiential learning component in bridging the gap between theory and practice. Mortiboys (2002) argued that learning and teaching strategies which directly target the development of student commitment and ability enhances their likelihood of staying the course and must be at the heart of any strategy to improve retention. According to the Council for Higher Education (CHE), (2013) the conditions on the ground in higher education institutions dictate a fundamental systemic review of the undergraduate curriculum. More programme time, more flexibility, more system self-awareness, and more rigour and steadfastness around the principles designed to hold the system together are needed (CHE, 2013)

Secondly in the area of support the findings show that being in foundation helps as you have more tutorials groups that are more structured and monitored and they assist with giving you a better understanding of the course. Whilst with mainstream tutorial groups are available but are not monitored as in foundation, so students attend as they please. Again the main difference between the two groups would be that the one has more time to go through the materials for the tutorials and the other everything is compressed within a semester. This view is supported by Warren, (2002) who argues that already within the semester period there is limited time available for support classes (tutorials, Supplementary instruction etcetera), combined with the fast pace and heavy volume of mainstream work, inhibits deeper learning, and this becomes more insufficient for 'bridging gaps' in learning. Christie, Munro, \& Fisher, (2004) supported by Blythman \& Orr, (2003) further argue that the majority of students do not seek support, therefore there should be an institutional strategy to build good support which will develop structures that reach all. McKenna, (2012) argues that differential access may result in provision of interventions and teaching methodologies aimed at providing epistemological access being directed only at those students allowed through alternative access routes (foundation programmes), leading to such 
interventions and approaches being withheld from students who enter the institution via traditional processes, despite the clear need for them to be provided the same opportunities as students entering through alternative access.

Lastly the issue of identity speaks to the stigmatization of foundation provisioning students. The findings highlight that in some instance foundation students are made to feel inferior and none deserving to be gain access to higher education. One of the respondents highlighted that they were referred to as 'DOM' which can mean anything from unintelligent to stupid. Warren, (2012) argues that programmes that are not integrated bring a certain level of resentfulness or stigmatisation, which may increase reluctance in students seeking assistance. Students may feel less motivated to attend classes and extra tutorial materials because of fear to be labelled by their peers. McKenna, (2012: 57) argues that 'foundational provision is often mistakenly understood as developing neutral skills in weak students whereas it should be considered from the position of interrogating the ways in which knowledge is constructed within different disciplines and then teaching and assessing in ways which make access to such ways of knowing available to all students'.

\section{Conclusion}

The study concludes that there are varying benefits and challenges in both mainstream and foundation offerings. There should be a more integrated way of differentiating these programmes such that challenges in durations of programmes, support and issues of stigmatization are totaling eliminated. The period of time to finish each programme needs to be taken into consideration through curriculum alignment. However there is no clear strategy currently in the institution for alignment of curriculum aspects like educational tours and extensive or more structured tutorial work for mainstream.

\section{Recommendations}

The study recommends that there be rethinking on curriculum alignment, to ensure that the students exit with the requisite skills, seeing that mainstream students feel disadvantaged in areas of support available for foundation students. We need to rethink why foundation provisioning year should not apply to all first year students entering to Higher Education especially if we are bridging the articulation gap between what first year student bring and the expectations of Higher Education. Given that in most faculties the offering of foundation programmes was still at its first triennium and that this was a limited sample, further research needs to be under taken to ascertain curriculum alignment between these two groups.

\section{References}

Breier, M., \& Mabizela, M. (2008). Higher education. Kraak A \& Press K (eds), 278-299.

Boughey, C. (2005). Epistemological Access to the university: An Alternative perspective. South African Journal of Higher Education, 19 (3), $638-650$.

Blythman, M. \& Orr, S. (2003). A joined-up policy approach to student support. In M. Peelo \& T. Wareham (Eds.), Failing students in higher education (pp. 45-55). Buckingham, UK: SRHE/Open University Press.

Christie, H., Munro, M., \& Fisher, T. (2004). Leaving university early: Exploring the differences between continuing and non-continuing students. Studies in Higher Education, 29(5), 617-636.

Council on Higher Education (CHE), 2013. A proposal for undergraduate curriculum reform in South Africa: The case for a flexible curriculum structure. Report of the Task Team on Undergraduate Curriculum Structure. Pretoria: Council on Higher Education (CHE).

Department of Education. (2001). National Plan for Higher Education. Pretoria: Department of Education.

DoE (Department of Education) (2006). Funding for foundational provision in formally approved programmes: 2007/08 to 2009/10. Pretoria: Department of Education.

Engeström, Y. (1993). Developmental work research: expanding activity theory in practice. Lehmanns Media.

Jansen J, 2004. Changes and continuities in South Africa's higher education system, 1994-2004. Linda Chisholm (ed) 2008: 293-314.

McKenna S 2012. The context of access and foundation provisioning in South Africa. In: R Dhunpath, R Vithal (Eds.): Alternative Access to Higher Education: Underprepared Students or Underprepared Institutions? Cape Town: Pearson, pp. 51-61.

Mortiboys, A. (2002). Retention as a measure of university effectiveness. Exchange, 1, 14-16.

SAPA (2008). University dropouts increase. Available at: http://news.iafrica.com/sa/917608.htm [Accessed March 21, 2014].

Scott, I. (2009). Academic development in South African higher education. In E.M.Bitzer (Ed): Higher education studies and research in South Africa: Some perspectives and themes. Stellenbosch: Sun Media.

Scott, I., Yeld, N., \& Hendry, J. (2007). Addressing diversity and development in South Africa: Challenges for educational expertise and scholarship. Cape Town: Council on Higher Education for the Improving Teaching and Learning for Success project. Unpublished.

Strydom, J. F., Mentz, M., \& Kuh, G. D. (2010). Enhancing success in higher education by measuring student engagement in South Africa. Acta Academica.

Vygotsky, L. S. (1978). Mind in Society: The Development of Higher Psychological processes. Cambridge, Mass: Harvard University Press.

Yorke, M. (2003). Academic failure: A retrospective view from non-completing students. In M. Peelo \& T. Wareham (Eds.), Failing students in higher education (pp. 29-44). Buckingham, UK: SRHE/Open University Press. 